Dr. Carlos Alberto Navarro Fuentes

Universidad Autónoma de la Ciudad de México (UACM)

@ betoballack@yahoo.com.mx

(iD) 0000-0003-4647-9961
- Recibido / Received

2 de junio de 2020

- Aceptado / Acepted 20 de junio de 2020

- Páginas / Pages De la 225 a la 238

- ISSN: 1885-365X

\title{
La visualidad en las nuevas humanidades. Arqueología y régimen escópico
}

\section{Visuality in the new humanities. Archeology and scopic regime}

\section{RESUMEN:}

El ensayo propone una aproximación a los estudios sobre la producción de significado cultural a través de la visualidad, subrayando la necesidad de enmarcar e historizar su análisis. Asimismo, incluir la arqueología en sentido foucaultiano, como investigación de los tránsitos del conocimiento, entre el utillaje expandido que el estudio de las prácticas de visualidad demanda, para continuar el análisis arqueológico de las distintas formaciones y regímenes escópicos dominantes de la modernidad al presente. Puesto esto en evidencia completar el trabajo crítico al apuntar posibilidades de transformación de los regímenes escópicos desde las nuevas potencialidades que se plantean en nuestra era.

\section{PALABRAS CLAVE:}

Arqueología; Visualidad; Régimen escópico; Episteme; Imagen.

\section{ABSTRACT:}

The essay proposes an approach to studies on the production of cultural significance through visuality, emphasizing the need to frame and historicizing analysis. Also include archeology in Foucault's sense, as research transits of knowledge between the tooling expanded the study of practices demand visuality, to continue the archaeological analysis of the different formations and dominant scopic regimes of modernity to the present. Since completing this critical evidence by pointing possibilities of transforming the scopic regimes from the new potentialities that arise in our era work.

\section{Introducción}

El último José Luis Brea, gran impulsor y teórico fundamental de los estudios visuales en nuestra lengua, proponía en Las tres eras de la imagen (Brea, 2010) dilucidar en diagonal la 
época en curso a través de la historia. Así, esas tres eras trazaban una cierta historia de los usos de la imagen hasta el presente a partir de una serie de desplazamientos tectónicos. En su obra establece una periodización que venía a diferenciar entre distintas construcciones de la episteme escópica, esto es, entre las diferentes reglas históricas que definen las condiciones de posibilidad de unos determinados regímenes y prácticas del ver en cada tiempo. ¿Cómo analizar el carácter producido de la visualidad en un marco histórico trazado a partir del modelo arqueológico? ¿De qué manera las formas técnicas para el darse de las imágenes han condicionado los regímenes escópicos de distintas épocas hasta el presente? ¿Qué transformaciones se están produciendo en cuanto al régimen escópico propio de nuestro tiempo?

\section{Los estudios visuales. Epistemología y metodología}

Las líneas más importantes sobre las que versará este ensayo corresponden al debate a partir de los lugares comunes y habituales, para justificar la emergencia de los estudios visuales. La cuestión del destacado rol de la cultura visual en las sociedades contemporáneas advierte la necesidad de desarrollar unos estudios centrados en la consideración y el análisis de las formas de la cultura visual de nuestro tiempo, se funda en la importancia que las imágenes y lo visual producido tiene en las sociedades actuales. Por una parte, el repertorio de los objetos de los que estos estudios han de ocuparse (principalmente las imágenes en tanto que productoras de significado y valor cultural y simbólico) crece cada día que pasa. Por otra, su impacto en la organización de los modos de vida reviste cada vez más importancia.

A partir de esta consideración sobre la potenciación del papel de la cultura visual en las sociedades contemporáneas, se propone implementar unos estudios capaces de abordar con rigor y solvencia este campo expandido de materiales y prácticas, al ser habitualmente no atendidos por unas $u$ otras disciplinas tradicionales construidas en torno a la especificidad de las prácticas culturales que estudian. La significativa expansión de intereses y objetos de estudio justifica la existencia de los estudios visuales, esto es, de propuestas rigurosas de aproximación analítico-críticas atentas a los efectos sociales, antropológicos y simbólicos que la presencia, la gestión y la circulación de lo visual tienen en el mundo actual.

La apertura del campo de objetos de estudio y la insuficiencia de las construcciones metodológicas y epistemológicas de las disciplinas dadas, conlleva al establecimiento de unos estudios que fomentan la sensibilidad y el interés por una aproximación crítica al amplio y complejo panorama de objetos, discursos y prácticas que configuran la visualidad en el presente, desde una perspectiva interdisciplinar capaz de abordar desde una multiplicidad de perspectivas los ámbitos políticos, económicos y socioculturales en los cuales están teniendo lugar las mencionadas transformaciones. Se trata de unos estudios que, como los propios objetos de los que se ocupan, tienen una naturaleza hibridada e interdisciplinar, habiendo de moverse sus intereses en un rango muy amplio que incluso oscila entre los propios estudios humanísticos (en los que como estudios orientados al análisis crítico del valor cultural tienen seguramente su raíz principal), los de la ciencia (donde el peso y la importancia de las imágenes y las representaciones crece constantemente) e incluso las ciencias sociales, toda vez 
que la consideración efectiva de la vida social de las imágenes como tal podría ser definida como el propósito propio de estos estudios.

La visualidad en la cuestión de las «nuevas humanidades», como parte del proceso de redefinición en que se encuentran los estudios de humanidades como consecuencia de la ampliación del campo de sus intereses y, en particular, del reconocimiento de la importancia cada vez mayor de las formaciones de la cultura visual de nuestro tiempo. Tradicionalmente, los estudios de humanidades se habían centrado casi exclusivamente en el estudio de «las letras», privilegiando el peso que el lenguaje ha tenido - en el seno de una tradición que bien podemos denominar «logocéntrica» - en la constitución del conocimiento y las formaciones del espíritu. En su atención a las nuevas formas de la cultura contemporánea, sin embargo, esos estudios humanísticos se han ido viendo cada vez más obligados a extender el campo de sus intereses. Así, en relación con el desarrollo de los estudios dedicados en toda su extensión al análisis cultural ha ido creciendo y asentándose un campo de estudios cada vez más relevante cuyo objeto central es la exploración crítica de las formas de la cultura visual contemporáneas en toda su amplitud.

La traslación del debate a las propias organizaciones académicas de los estudios visuales surge como iniciativa curricular en el contexto académico de los Estados Unidos alrededor de 1990. En las últimas décadas, los programas dedicados a los estudios visuales han proliferado en el ámbito de las instituciones académicas, establecidos en diferentes direcciones a partir de la demanda de formación cualificada de especialistas capacitados y comprometidos con el conocimiento crítico y la gestión responsable del papel crucial que tienen en nuestro mundo las prácticas simbólicas ligadas a la producción, distribución y recepción de las imágenes.

Así, el origen de la demanda de estos estudios es por tanto doble, y proviene no menos de la expansión de las llamadas industrias del imaginario - que reclama la formación de profesionales capacitados para incorporarse a su gestión activa de un modo innovador y creativo - que del propio tejido ciudadano, necesitado igualmente de especialistas capaces de favorecer y optimizar - por la mediación del análisis cultural - la recepción crítica de esos mismos flujos de transferencia de imaginario $-y$ de sus múltiples dependencias de todo tipo de intereses - a los que la potenciación de las industrias asociadas otorga cada día que pasa mayor capacidad de impacto y relevancia social.

La función de las prácticas de visualidad en la generación de riqueza en las sociedades del conocimiento, incide en el enorme crecimiento que en los últimos años ha tenido el sector ligado a la expansión de las llamadas industrias creativas y de la producción de contenidos, del que las industrias del imaginario forman sin duda una parte esencial, tanto por su importancia en los procesos de la contemporánea «estetización de la mercancía» como por su peso en el crecimiento y la expansión de las nuevas industrias del entretenimiento - las de la comunicación y producción de contenidos, en su nueva alianza con las propiamente culturales - , la producción de imagen en las sociedades contemporáneas representa una de las fuentes activas más importantes en los nuevos procesos capaces de generar valor.

Si hasta en las sociedades industriales la producción simbólica - de narrativas e imaginarios colectivos - disfrutaba de un estatus propio con respecto a las formas generales de la producción, en las sociedades del conocimiento en cambio, descritas por varios autores como sociedades del «capitalismo cultural», la producción simbólica está pasando a ostentar un estatus plenamente integrado al sistema general de la producción, tanto que poco a poco 
su sector tiende a convertirse en el centro motor mismo de los nuevos procesos de generación de riqueza, caracterizando ello lo que en el contexto de las nuevas economías algunos autores han descrito como el contemporáneo despliegue de una fase postfordista del capitalismo avanzado, en que el «trabajo inmaterial» y todo el orientado a la producción simbólica se convierte en uno de los escenarios principales de desarrollo.

En nuestra aproximación a los estudios visuales, nos recordaba José Luis Brea, guía esencial de este ensayo, que Debord y los situacionistas nos mostraron cómo para alcanzar un momento elucidatorio acerca de un determinado periodo, debemos trabajar con los mecanismos de producción técnica propios de esa era. Así, si queremos emprender la tarea de pensar críticamente el presente desde su estudio como problema histórico, nos corresponde emplear las nuevas condiciones técnicas ya plenamente dadas e implementar los distintos modos de producir sentido que se puedan acoger, experimentando con los elementos críticos propios de una epistemología de la era electrónica.

Más allá de la revisión de las propias condiciones del ejercicio de análisis crítico, incidiremos en uno de los presupuestos generales de los estudios visuales, en la construcción social de la visión y en su dimensión histórica. Así, insistiremos en subrayar el carácter producido de lo visible y propondremos una investigación sobre las distintas construcciones de cada episteme escópica, sobre las prácticas del ver, la mirada y las tecnologías de la visión dadas desde la modernidad hasta el presente. En ese recorrido se analizará el tránsito entre las distintas eras de la imagen, y en particular la discontinuidad que conduce a la presente era de la imagen electrónica. De esta forma, aplicaremos el análisis arqueológico, en un sentido foucaultiano, en la exploración del conjunto de reglas históricas que definen en una determinada época las condiciones de posibilidad de unas imágenes, de unas prácticas del ver, es decir, de aquello que cada época considera verosímil con relación a lo visible o, en los términos aplicados por Martin Jay, de determinados regímenes escópicos. Para atender a ello, hemos trazado el ensayo desde una comprensión de la tarea propia de los estudios visuales como proceder analítico-crítico en relación con prácticas artísticas y culturales sostenidas en la circulación de imágenes en un tiempo y una circunstancia social determinada.

Como es común advertir, la necesidad de desarrollar unos estudios centrados en la consideración y el análisis de las formas de la cultura visual de nuestro tiempo se funda en la importancia que las imágenes y lo visual producido tienen en las sociedades actuales. Por una parte, el repertorio de los objetos de los que estos estudios han de ocuparse - principalmente las imágenes en tanto que productoras de significado y valor cultural y simbólicocrece cada día que pasa. Por otra parte, su impacto en la organización de los modos de vida reviste cada vez más importancia. Se hace necesario implementar unos estudios capaces de abordar con rigor y solvencia este campo expandido de materiales y prácticas al ser habitualmente no atendidos por unas $\mathrm{u}$ otras disciplinas tradicionales construidas en torno a la especificidad de las prácticas culturales que estudian.

Esta significativa expansión de intereses y objetos de estudio justifica la existencia de los estudios visuales, esto es, de propuestas rigurosas de aproximación analítico-críticas atentas a los efectos sociales, antropológicos y simbólicos que la presencia, la gestión y la circulación de lo visual tienen en el mundo contemporáneo. Se proponen así unos estudios que fomentan la sensibilidad y el interés por una aproximación crítica al amplio y complejo panorama de objetos, discursos y prácticas que configuran la visualidad en el presente, desde una pers- 
pectiva interdisciplinar capaz de abordar desde una multiplicidad de perspectivas los ámbitos políticos, económicos y socioculturales en los cuales están teniendo lugar las mencionadas transformaciones. Estudios que como los propios objetos de los que se ocupan, tienen una naturaleza hibridada e interdisciplinar, habiendo de moverse sus intereses en un rango muy amplio que incluso oscila entre los propios estudios humanísticos (en los que como estudios orientados al análisis crítico del valor cultural tienen seguramente su raíz principal), los de la ciencia (donde el peso y la importancia de las imágenes y las representaciones crece constantemente) e incluso las ciencias sociales, toda vez que la consideración efectiva de la vida social de las imágenes como tal podría ser definida como el propósito propio de estos estudios.

Al desplazarse la visualidad en cuanto a modos de producción y función, se crean nuevas o diferentes significaciones culturales que como dice Brea, constantemente se están actualizando. Ahora bien, ¿cómo vamos a procesar y decodificar estas imágenes que devienen en un presente que no termina? Y además ¿cómo estudiar ese proceso cognitivo? Si con la llegada de la imprenta se democratizó la palabra escrita, y se requirió que más personas aprendieran a leer y escribir, ¿se podría hablar ahora de una educación visual? Tal vez el estudio o conocimiento por medio de un texto sea diferente puesto que tiene un orden y una linealidad, mientras que la imagen contiene una parte visual y una discursiva que se presenta al mismo tiempo.

Foucault, en su obra Las palabras y las cosas. Una arqueología de las ciencias humanas (Foucault, 2005), preguntaba acerca de la obra del pintor Velázquez Las Meninas, si los «actores» representados en esta ¿nos veían o los veíamos nosotros a ellos? De esta manera, la relación de miradas nos incluye a nosotros como espectadores, donde antes se suponía que sólo estaban los actores y el pintor. El espejo hace oscilar el adentro y el afuera de este, el pintor puede estar en cualquier parte del cuarto en donde se pinta la obra, así Velázquez abre un espacio a la mirada anteriormente desconocido para la representación, mostrándonosla en su pureza. «Foucault hace visible lo invisible hasta finales del siglo XVIII» (Riquelme, 2007: 2). Por eso afirma Deleuze,

En Foucault los lugares de visibilidad nunca tendrán el mismo ritmo, la misma historia, la misma forma que los campos de enunciados, y la primacía del enunciado sólo será válida por esa razón, en tanto que se ejerce sobre algo irreductible (Deleuze, 2007: 78).

De la misma manera, el modo de observar y el lugar de quien observa cambiaron respecto de la época clásica. Deleuze resaltaba la importancia de los análisis sobre el ver y del modo de ver de Foucault, como parte central y constante en su trabajo, tanto en sus historias como en su pensamiento. En su obra Foucault, Deleuze insiste en la mutilación que sufre el pensamiento cuando no se tiene en cuenta «la teoría de las visibilidades». «Lo más característico de él es la voz, pero también los ojos. Los ojos, la voz» (Deleuze, 2007: 78). Así, Deleuze dice de Foucault, ser un pensador «audiovisual», cuya problemática «está muy cerca de la del cine contemporáneo» (Deleuze, 2007:94). Resulta oportuno subrayar el mayor obstáculo en la tarea del archivista: su inabarcabilidad, como problematización fundamental. El archivo de una época no es descriptible en su totalidad, más aún cuando el periodo es el propio y ese archivo marca las reglas de nuestro discurso. La tarea sólo alcanza a realizar el archivo de dominios discursivos y modos de visibilidad concretos.

La determinación de esa concreción marca la actividad del archivista y considerando que cualquier selección conlleva siempre un «sencillo fracaso». Michel De Certeau también ha subrayado el estilo ocular de los escritos de Foucault, de los cuales dice: 
Los trabajos están salpicados con tablas e ilustraciones [...] El discurso entero procede de esta forma de visión a visión. El paso que marca el ritmo de la marcha hacia delante del discurso, en el que esa marcha encuentra apoyo y del cual recibe su impulso, es un momento visual (De Certeau citado en Jay, 2007: 289-328).

De acuerdo con De Certeau, Foucault habría usado la visión para socavar la propia visión.

Mientras el libro analiza la transformación de las ideologías de la ilustración por la maquinaría panóptica, su escritura es una subversión de nuestras concepciones panópticas contemporáneas por las técnicas retóricas de la narrativa (De Certeau citado en Jay, 2007: 289-328).

Foucault, en su curso sobre la pintura de Manet, da un claro ejemplo de cómo la pintura es capaz de representar lo «invisible», como si las imágenes quisieran retornar al espacio imaginado del cual provienen para entrelazarse con el entorno que las genera. Siendo optimistas y esperando por lo que las imágenes querrían decirnos, en Manet y Velázquez se encuentra la posibilidad de que las imágenes necesiten salirse del espacio que las contiene, tal vez necesiten compañía y aluden al espectador a ser partícipe, devolviéndole la mirada e incluyéndolo. Mostrando distintos ángulos por medio de espejos, escenas no vistas, partes de lienzo sin pintar que recuerdan al lienzo del cual forman parte, por medio de escenas inconclusas o recortadas que dirigen la mirada hacia el afuera, a lo que no encontraremos en el cuadro que contemplamos.

Martín Jay destacaba, «las figuras ópticas de Foucault aparentemente evidentes, claras y transparentes eran subvertidas por el modo en que se presentaban" (De Certeau, 1982: 264). Jay ha insistido en una cierta ambivalencia con respecto a lo ocular en Foucault. Si en ocasiones este usa el poder de las imágenes, a menudo, y esta es la tesis principal de Jay, el trabajo de Foucault se corresponde con el discurso antivisual del pensamiento francés del pasado siglo. «La visión era todavía el sentido privilegiado, pero lo que ese privilegio produjo en el mundo moderno era condenado como casi por completo pernicioso» (Jay, 2006). Esta consideración dio lugar a una polémica en la que han tomado posición buena parte de los autores que se han ocupado de Foucault con relación a la visión en las últimas dos décadas.

John Rajchman afirma, «si uno reemplaza "lo visual" por "lo racional" en esta formulación, uno encuentra un patrón familiar de descalificación del pensamiento francés contemporáneo» (Rajchman, 1988: 90). Las posiciones contrarias a la mantenida por Jay cuestionan que Foucault sospechara de la hegemonía del ojo en todas sus manifestaciones. Más tarde Jay conciliaba en cierto modo las diferentes posiciones, afirmando que a pesar de su lamento sobre estar atrapado en el «imperio sin límite de la mirada» (Rajchman, 1988: 90), Foucault entendió efectivamente que el poder de ese imperio es limitado. Así, en el régimen escópico moderno, existían prácticas visuales alternativas y estas pudieron ser fructíferas, aunque no pudieron en ningún caso, restaurar la completa inocencia del ojo.

Mieke Bal ha recurrido a la consideración más constructiva de Rajchman acerca de la visión en Foucault, como «proveedora de una clara comprensión de las razones por las que el trabajo de este, y a pesar de todos sus recelos de la visión, debe ser visto como una poderosa herramienta para trabajar críticamente con la visión» (Bal, 1993: 391). Esta consideración de Bal a partir de Rajchman, puede ser extensible a buena parte de los textos, de los diferentes puntos de vista a que nos hemos referido y que sumados forman la guía de usuario de 
la caja de herramientas foucaultiana que hemos empleado en nuestra investigación. En la actualidad, los estudios visuales, han producido una revolución en el estudio de las prácticas artísticas y culturales de carácter crítico, específicamente de la imagen en donde la electrónica y la virtualidad, el capitalismo semiótico y cognitivo, y la globalización neoliberal, sirven de trasfondo y estructura para el campo del arte en todo su conjunto.

Por consiguiente, este diferencial epistemológico-crítico para los «objetos» del arte y de la cultura, de la estética y de la historia del arte incluidos, requieren de un nuevo aparato epistemológico y metodológico para su estudio, que le capaciten mejor para la salida de este dilema mencionado, sin que ello signifique un rompimiento epistemológico total con el predominante, sino a través de mediaciones transversales, transdisciplinares e interculturales acordes con la complejidad, tradiciones y dimensiones significantes (hermenéutica, semiótica, lingüística, entre otras) que estos estudios requieren.

En términos deleuzianos, estas categorías aquí propuestas, funcionarían como las «máquinas de guerra» o «caja de herramientas» con las cuales epistémicamente nos batiríamos en el campo de la teorización, producción de significado y efectos socioculturales, metodología, práctica, análisis y critica de las artes visuales. Darle sentido y verdad a lo anterior, implica no tanto una intervención de carácter cognitivo en la tradición sino en un sentido analítico-crítico, es decir, no hegemónico, uniforme ni hermético, por lo que Brea propone que estos estudios se constituyan como «estudios (culturales) sobre lo artístico (estudios culturales-visuales artísticos, estudios culturales-visuales televisivos, etc.)» (Brea, 2005: 22), permitiendo y contribuyendo a que dicho carácter de intervención crítica no se fije ni siquiera por el uso y la costumbre como nuevo molde único aceptado, como dogma de fe, ni como relaciones bilaterales entre "objetos» y «conceptos» o «definiciones», sino que su simbolicidad permita una circulación pública en constante desmantelamiento y propagación; como estudios de la vida social de los objetos visibles.

En virtud de lo anterior, la crítica

Necesita ejercer el distanciamiento que le permita postular su propio trabajo productivo simbólico en un terreno de des-implicación efectiva con la constelación de presuposiciones fiduciarias que sostienen el funcionamiento práctico de la institución- Arte con la que se relaciona (Brea, 2005:25).

De esta manera, la crítica de arte en tanto crítica debe dislocarse y superar «la fe en el arte», esta última ya no basta. Esto conllevaría a afirmar que el punto de partida de

los estudios visuales sería, la convicción de que ni existe tal pureza fenoménica de lo visual en ámbito alguno ni aún en su designio existe nada abordable como tal naturaleza, sino únicamente, como resultado -y aún como agenciamiento- de una producción predominantemente cultural... (Brea, 2005: 23).

El papel de la crítica sería

Intentar poner al desnudo el sistema de enunciados, prácticas y formaciones institucionalizadas implícito - los dogmas de fe- que sostienen como formación estable la propia estructura funcional en cuyo espacio público efectivo se despliega la práctica artística, como práctica de interacción social (Brea, 2005: 25-26). 
Esto significa, que la crítica sea capaz de llegar hasta el lugar en el cual las prácticas culturales producen sus «objetos» y los supuestos epistemológicos y conceptuales que los sostienen. El orden de visibilidades entra en tensión, en conflicto, en un campo de batalla en donde interactúan y participan desterritorializándose y reterritorializándose, deconstruyéndose y reconstruyéndose en multiplicidad de modalidades diferenciales e identitarias, redefiniendo así los códigos, los registros, los campos, los signos, las formaciones culturales dominantes postcoloniales y los imaginarios en donde habitan, problematizando y complejizando la arquitectura y la epistemología, la génesis, la herencia y el desarrollo en la cual intervienen.

\section{Formaciones escópicas de la modernidad}

¿Cómo analizar el régimen escópico de un periodo? ¿Qué caracteriza el régimen escópico de la modernidad? Reflexionaremos sobre el análisis arqueológico con relación al estudio de las formaciones y los regímenes de la visión de la modernidad. A partir del desplazamiento entre eras se analizarán cuestiones clave sobre el establecimiento de esos regímenes sistémicos, audiovisuales, escópicos, desde los cuales entender «el ver» construido en una época, pero también sobre los objetos de estudio. Para Brea, la imagen educa nuestro modo de ver haciendo pasar de lo que es o podría ser mera espontaneidad a conocimiento compartible culturalmente por el contexto espacial en el cual tiene lugar. «La imagen-cuadro organiza la arquitectura de lo visible conforme a un cierto programa, de un modelo histórico-cultural, en efecto» (Brea, 2010:23). En este sentido, la lógica del ver como devenir puramente natural, sensorial y fenoménico de la tradición ocularocentrista no aplica ya como existenciario organizativo del ver y de la mirada, pues acaece una revolución epistemológica y cultural en los mismos actos de ver, convirtiéndose «lo del mundo» que puede ser visto, en una pantalla porosa sobre la cual se reescribe.

Dice Brea,

Pese a que la descripción analítica de este esquema parezca ardua y el proceso del que se habla, complejo, en realidad es una lógica instantánea que se resuelve en un solo acto psíquico -en un único golpe de vista (Brea, 2010: 24).

La arquitectura como paradigma del régimen escópico que prevaleció como objetividad durante siglos se ve alterada, el imaginario y el sujeto que ve atraviesan por ciertas desterritorializaciones en «los modos de producción, las formas de la economía, las estructuras de poder, la construcción de las formaciones de sujeción, etc...» (Brea, 2010: 26).

La comprensión de la vida psíquica con relación al pensamiento estético y la variante epistemológica en el régimen escópico, deviene en gran parte como forma de inconsciencia, ya que «hay algo en lo que vemos que no vemos, o mejor aún, hay algo en lo que vemos que no vemos que vemos, que no sabemos que vemosz" (Brea, 2010: 58). Por consiguiente, no sólo hay una desterritorialización, sino que también opera una desocultación de lo óptico en la ideología estética. La obra de arte más que ocultar, desoculta, revela el ser, lo verdadero más allá de lo puramente retiniano, «desoculta lo no visto en lo visto» (Brea, 2010: 59). Esto es, el inconsciente óptico, «ese algo que no vemos instalado en el centro mismo de la visión» (Brea, 2010: 59). 
Lo anterior, produce relaciones articuladas de nuevo conocimiento y saber, de sentido y de comprensión que impactan en el modo en el que el mismo régimen escópico se conforma, haciéndolo transparente, perfecto, total, en el cual todo puede verse desde cualquier posición y ángulo (hipervisión). El panóptico se torna absoluto, contrario a la dogmatización estructurante del capitalismo críptico y semiótico que intenta invisibilizar, controlar y hegemonizar la mirada y lo mirado, lo visible y la vista de acuerdo a su propia lógica de organización y poder, regulando la visualidad acorde con su propio régimen de vigilancia, control, disciplina y administración panóptica, hasta adquirir una naturaleza distributiva performativamente acorde con su metafísica biopolítica en tanto positiva frente a toda crítica, apertura y negatividad. Por ello, afirma Mieke Bal,

Pero los conceptos sólo pueden realizar esta tarea, la tarea que antes realizaban las tradiciones disciplinares, con una condición: que se sometan a escrutinio no sólo en su aplicación a los objetos que examinan, sino también en la confrontación con ellos, ya que los objetos mismos son sensibles al cambio y revelan en ellos el despliegue de las diferencias, históricas y culturales (Bal, 2006: 27-77).

Las imágenes no sólo nos aportan conocimientos y saber, sino que tienen un saber específico. Es posible pensar que estas también gozan de uno propio y pueden ser conocidas, además de ofrecernos contenidos y efectos de conocimiento, pues no carecen de lenguaje, de signos, de fórmulas, de técnicas, de discursividad, de símbolos, entre otros elementos, propios de un régimen en donde se establecen relaciones entre objetividad y subjetividad propios y afines a una «totalidad borrosa» y una arqueología flexible y fluyente de significados y objetos que se organizan y ubican en territorios diversos, cambiantes y no excluyentes, que acuden a articulaciones, redes y tensiones diversas resultando que para su análisis requieren de una epistemología transdisciplinar desde la parte metodológica misma y confluyendo en lo que ya hemos hablado en torno a unas «nuevas humanidades», con sus propios horizontes y formaciones discursivas, más rizomáticas que arborescentes en cuanto a su forma. De allí que Susan Buck-Morss afirme que

Los Estudios Visuales proporcionan la oportunidad de iniciar una transformación del pensamiento a escala general [...] el carácter evasivo de los Estudios Visuales concede a este espacio la elasticidad epistemológica necesaria para encarar la actual transformación de las estructuras de conocimiento existentes, cada vez más agotadas institucionalmente en todo el mundo (Buck-Morss, 2005: 145).

\section{Regímenes de la imagen electrónica}

Reflexionamos sobre el nuevo escenario determinado a partir del asentamiento de la imagen electrónica. Un nuevo devenir de la cultura con unas distintas formas de producción, distribución y recepción producidas por las nuevas tecnologías de lo visible. Así mismo, tras ese último salto epistémico, se sugieren distintos escenarios para los propios estudios críticos. El espectador mismo y su visión -incluyendo al ojo como sentido de la vista -, la relación entre lo visible y lo invisible, la relación entre la mirada y el lenguaje, y así, entre el espectador y el mundo, cambiaron también. De esta forma, no extraña que ese determinado trayecto histó- 
rico descrito en Las tres eras de la imagen (Brea, 2010) concluya trazando los perfiles de un horizonte utópico. Una utopía como búsqueda de líneas de fuga en un momento de crisis y ruptura, como única salida en una situación en la que las demás opciones están agotadas, aunque todavía ejerzan su fuerza normativa.

Brea encuentra esa posibilidad en la imagen contemporánea, en la imagen electrónica, la e-image. A partir de la última condición de la imagen, Brea empieza a dibujar esas líneas de fuga que se asoman a la emancipación, a la crítica y a la utopía. Así, se revelan las posiciones contrapuestas de Crary y Brea; mientras Brea afirma que estamos en un momento en que una nueva era está emergiendo, Crary niega que estemos experimentando un cambio de paradigma en el que, digamos, la cultura digital esté sustituyendo a la cultura tipográfica. ¿Podemos o no afirmar que asistimos en el presente a un cambio de época vinculado al advenimiento de los medios digitales? ¿Nuestra experiencia visual está desactivada, modulada o aumentada ante una multiplicidad cada vez mayor de estímulos psíquicos infundidos por unas tecnologías de comunicación y de entretenimiento cada vez más sofisticadas? ¿Se puede pensar críticamente el presente a partir de tránsitos históricos anteriores definidos por innovaciones tecnológicas específicas? ¿Qué rol desempeñan las imágenes en el funcionamiento de las instituciones hegemónicas de las sociedades actuales? ¿Pueden emplearse las condiciones tecnológicas actuales como herramientas al servicio de una política emancipatoria?

Para Brea, la constitución del campo escópico es cultural, dado que subyace sometido a

construcción, historicidad y culturalidad, al peso de los conceptos y categorías que lo atraviesan [...] El ver no es neutron ni, por así decir, una actividad dada y cumplida en el propio acto biológico, sensorial o puramente fenomenológico. Sino un acto complejo y cultural y políticamente construido... (Brea, 2007: 181-182).

En este sentido, arte sería el resultado contextual historico y cultural, como actividad simbólica acorde con las condiciones de posibilidad que ofrece un régimen escópico determinado. Es decir, los regímenes escópicos de cada época, sociedad y cultura en su desarrollo histórico, valorarán y condicionarán los regímenes de creencia y los actos de ver, de los cuales depende la supervivencia del arte.

Por otro lado, en la e-image

se da en cambio en condiciones de flotación, bajo la prefiguración del puro «fantasma» [...] Su paso por lo real es necesariamente efímero, falto de duración. Ella comparece, pero para inmediatamente desvanecerse, ceder su lugar a algo otro. Su modo de ser es al mismo tiempo un sustraerse, un estar pero permanentemente dejando de hacerlo (Brea, 2007: 186).

Por ello, en la imagen electrónica, dice Brea,

la naturaleza de la disposición mnemónica se altera radicalmente, de tal modo que toda su energía simbólica se desvía para dejar de dar bajo la prefiguración de la conservación y el recuerdo, abandonando acaso la égida de mnemosyne, de la promesa de duración (Brea, 2007: 188).

De esta manera, las nuevas formas del capitalismo global neoliberal contemporáneo se insertan a las mismas lógicas de distribución social, incluyendo a la «economía de la memo- 
ria» como característica de la e-image a propósito de las nuevas formas de ver de la sociedad compleja actual, cuyo desarrollo técnico no aflora desfasado las circunstancias culturales del imaginario con el cual tiene correspondencia. Las imágenes producen conocimiento en tanto son compartidas y colectivizadas, lo cual no significa universalidad, sino que en su propia fragmentariedad y multiplicidad a la cual conllevan la conformación de nuevos modos de hacer comunidad de manera compartida, a través del consumo simbólico de la mencionada e-image. Por ello, como dice Valery, «habrá economías y sociedades en las que la realidad sensible pueda llevarse a domicilio", introduciendo así formas de recepción para el consumo cultural y economías de la propiedad común del conocimiento.

En la historia de lo simbólico, la tecnología y la aspiración democrática deben confluir en un horizonte común. Crary utilza el lema 24/7, el cual anuncia un tiempo sin tiempo, sin secuencia ni repetición, es decir, una temporalidad imposible. «El fin de semana es el residuo moderno de esos sistemas arcaicos, pero incluso esta marca actual de diferenciación temporal resulta erosionada por la imposición de la homogeneidad del 24/7» (Crary, 2015: 42). Dicha homogeneidad no implica una eliminación de la experiencia, sino su empobrecimiento y reducción a su mínima expresión. Las innovaciones tecnológicas no acaban por ofrecer -al igual que las bonanzas capitalistas - las gratificaciones esperadas del orden económico mundial y su supuesto régimen democrático, que hacen del mundo un mundo invivible. «La externalización del individuo en un sitio de escrutinio y regulación que no cesa, establece una continuidad con la organización del terrorismo de Estado y el paradigma de absoluto dominio de lo militar-policial» (Crary, 2015: 43).

No hay imágenes gratuitas o inútiles, como el cambio tecnológico tampoco acontece de manera autónoma y fortuita, enteléquica y autooorganizadamente y sin alteraciones en la experiencia y la percepción. Por ello, afirma Crary que

los ciclos de reemplazo anteriores eran lo suficientemente largos como para, por lo menos, posibilitar la ilusión consensual de una semipermanencia que dominar por un tiempo [...] La aceleración de la producción de las novedades es una desactivación de la memoria colectiva (Crary, 2015: 54-55).

No hay escape ni salvación a estos principios de sometimiento, pues intentar abstenerse o rebelarse, revela la frustración, el fracaso y la amenaza del aislamiento o incluso la expulsión de la comunidad. Lo anterior sucede, mientras creemos denodadamente que «dichos patrones sistémicos están para quedarse y que tales niveles de consumo tecnológico se extienden a la población del planeta, que oscila entre los siete mil y los diez mil millones» (Crary, 2015: 58).

Retomando dos cuestiones específicas que plantea Roberto Riquelme (2007) sobre cómo los dispositivos de este periodo no admiten imágenes materia al no ser evacuadas estas por completo, así como el cuestionar si la crítica debe de pasar por la forma red o en su defecto objetarla, creo que la crítica efectivamente debe de considerar como base la forma red, siguiendo a Crary cuando hace referencia a los dispositivos inteligentes y a los recursos en red que permean cada aspecto de lo social y la vida personal al integrar un ininterrumpido acceso de 24/7 en nuestras rutinas cotidianas que llevan a más personas a levantarse de la cama y poner fin al concepto de descanso - descanso que se pensaba en cierto momento regulado por la ausencia de luz solar» y sustituirlo por la posibilidad de checar sus mensajes o información a cualquier hora (Crary, 2015: 13; 33: 84). 


\section{Conclusiones/Discusión}

Sobre el recorrido que va de la lógica de la visión desplegada como teoría de la verdad, hasta el último periodo de hipervisibilidad potencialmente absoluta de las tecnologías electrónicas, fue nuestra intención principal subrayar cómo este régimen escópico de la total transparencia y accesibilidad universal, donde todo puede ser visto, donde las imágenes pueden distribuirse en un flujo permanente y universal, no abandona el estado de potencialidad virtual. Sobre ese escenario hipotético se impone un régimen regulador que desproduce y regula la imparable abundancia, para distribuir la lógica de la visibilidad en zonas de completa visión frente a otras de visibilidad mermada o completamente ciegas, en zonas de control y supervisión frente a otras vigiladas, convertidas en espacios sometidos a mirada, pero incapacitados para ejercerla activamente en proporción de igualdad.

Simultáneamente se escasea la productividad de las imágenes mediante mecanismos diversos, y sobre todo la universalidad de su acceso y propiedad. De acuerdo con Brea, la imagen electrónica ya no reconoce sus obligaciones para con una lógica narrativa ni histórica alguna, en ella la temporalidad está condensada en el instante convergente, indistinguible, de la producción-distribución-recepción. Nada repite a nada, nada resuena en nada, ni siquiera nada pide ser secuenciado según órdenes de cronicidad como la sucesión de cada antes con cada después.

Como interpretaba Sergio Martínez (2009: 102-113), el tiempo de la imagen no es más el tiempo de organización de la diferencia en el flujo dialéctico, causal, del antes y el después, sino que aquel implosiona en el interior de la propia imagen, que acaba por referirse sólo a sí misma, a su propio devenir como diferencia. Toda la articulación de las imágenes entre sí se juega bajo el signo de la diferencia. En ese contexto, Brea apuntaba al omnipresente carácter matricial, también para las estructuras de producción de las imágenes electrónicas, como pura potencia de flujo y deriva, derrape y encuentro de todo con todo no sometido a una regulación de identidad de ningún orden. Reencontramos otra cuestión recurrente para el debate, como garantizar la producción de sentido, como producir un conocimiento efectivo, y ahí es donde para Brea entra en juego la construcción general de una nueva epistemología, tanto para los productores de simbolicidad como también de la criticidad.

Otra cuestión sería si la producción de criticidad en el presente debe pasar por la forma red o al contrario debe objetarla. De acuerdo con Brea, una única restricción desarrollada en dos trayectos, el de la sociedad de control a partir del poder de regulación escópica de los dispositivos técnicos propios de la era de la electrónica y, por otra parte, aquel empeñado en defender el carácter propietario de las imágenes producidas, como si ellas pudieran pertenecer a otro orden que el de lo común.

En Las tres eras de la imagen, señala un horizonte de utopía, de ejercicio de resistencia, para las prácticas de imaginario. El horizonte de la reposición de su escenario de hipervisión y comunitariedad, realizado mediante la apropiación de los medios y las condiciones que hacen posible su producción y libre agenciamiento para la totalidad virtual de los sujetos de experiencia. Así, Brea propuso como características de este nuevo regimen (Brea, 2007: 196):

- La desviación de la fuerza simbólica asociada a la imagen hacia la percepción del sentido-acontecimiento, como reconocimiento del diferirse de la diferencia en cuanto al tiempo. 
- El reconocimiento del character mental, psi, de la imagen, disociada cada vez más de la exigencia de espacialización y materialización en objeto específico y singularizado.

- La puesta de su fuerza simbólica al servicio de la producción cognitiva (heuristica) -ya no archivística, mnemotécnica- y de la generación de procesos de socialización, productores de comunidad.

- La apertura del régimen social de circulación de la imagen a la forma de las economias de la distribución.

- La orientabilidad última del proceso a formas de apropiación colectiva del conocimiento e intelección colectiva.

Crary nos hizo reflexionar con su lema 24/7, que la omnipresencia de ambientes de este tipo en las sociedades contemporáneas, resulta ser una condición correlativa al capitalismo global, que ha contribuido al aplanamiento homogeneizante más que a la complejidad heterogeneizante y plural, que ha socavado hasta la decrepitud las temporalidades diferenciadas de las diversas comunidades que habitan el planeta, en gran parte no sin la ayuda gestiva y ciertas prácticas de inclusión dogmática y unilateral de las redes y mercados que funcionan 24/7, es decir, las 24 horas del día los 7 días de la semana.

La cultura visual tiene una genealogía que necesita ser estudiada y definida tanto en el periodo moderno como en el postmoderno. A lo largo de este ensayo nos aproximamos a los análisis de la visualidad occidental moderna desarrollados por Jonathan Crary y Martin Jay, nos introdujimos en el arsenal metodológico provisto por Michel Foucault y hemos analizado el emplazamiento, desplazamiento, sobreposición y cohabitación de distintos regímenes audiovisuales, según José Luis Brea.

\section{Bibliografía}

BAL, Mieke (2006). «Conceptos viajeros en las universidades». En Estudios Visuales, 3, 27-77.

BAL, Mieke (1993). «His master's eye». En Levin, David Michael (Ed.). Modernity and the hegemony of vision. Berkeley, University of California Press.

BREA, José Luis (Coord.) (2005). Estudios visuales. La epistemología de la visualidad en la era de la globalización. Madrid: Akal.

BREA, José Luis (2007). «Cambio de régimen escópico: del inconsciente óptico a la e-image». En Cultura RAM. Mutaciones de la cultura en le era de su distribución electrónica. Barcelona: Gedisa.

BREA, José Luis (2010). Las tres eras de la imagen. Imagen-materia, film, e-image. Madrid: Akal.

BUCK-MORSS, Susan (2005). «Estudios visuales e imaginación global». En Brea, José Luis (Coord.). Estudios Visuales. Estudios visuales. La epistemología de la visualidad en la era de la globalización. Madrid: Akal.

CRARY, Jonathan (1989). «Spectacle, attention, counter-memory». October, 50, 96-107. DOI: $10.2307 / 778858$

CRARY, Jonathan (2008a). Las técnicas del observador. Visión y modernidad en el siglo XIX. Murcia: Cendeac.

CRARY, Jonathan (2008b). Suspensiones de la percepción. Atención, espectáculo y cultura moderna. Madrid: Akal. 
CRARY, Jonathan (2015). 24/7: El capitalismo al asalto del sueño. Barcelona: Ariel.

DEBORD, Guy (1999). La sociedad del espectáculo. Valencia: Pre-Textos.

DE CERTEAU, Michel (1982). «Micro-techniques and panoptic discourse: A quid pro quo». Humanities in Society, 5(3/4).

DE CERTEAU, Michel (1986). «La sonrisa de Michel Foucault». En Heterologías: Discurso sobre el otro. Minneapolis, p. 196.

DELEUZE, Gilles (1999). «Post-scriptum sobre las sociedades de control». En Deleuze, Gilles. Conversaciones 1972-1990. Valencia: Pre-Textos.

DELEUZE, Gilles (2007). Foucault. Barcelona: Paidós.

FOUCAULT, Michel (2005). Las palabras y las cosas. Una arqueología de las ciencias humanas. México: Siglo XXI.

FOUCAULT, Michel (2012). Vigilar y castigar: nacimiento de la prisión. Buenos Aires: Siglo XXI.

JAY, Martin (2002). «Regímenes escópicos de la modernidad». En Jay, Martin. Campos de fuerza. Entre la historia intelectual y la crítica cultural. Barcelona: Paidós.

JAY, Martin (2006). «Visual Parrhesia? Foucault and the Truth of the Gaze». Conferencia pronunciada en el curso Los Estudios Visuales: geopolíticas de la imagen en la sociedad del conocimiento. IV Foro Internacional de Expertos Arte Contemporáneo, ARCO, Madrid.

JAY, Martin (2007). Ojos abatidos. La denigración de la visión en el pensamiento francés del siglo xx. Madrid: Akal, págs. 289-328.

MARTÍNEZ, Sergio (2009). "La crítica de la cultura después de la cultura». Estudios Visuales, 7.

MITCHELL, W.J.T. (1994). Picture theory. Essays on verbal and visual representation. Chicago: University of Chicago Press.

RAJCHMAN, John (1988). «Foucault's art of seeing». October, 44, 88-117. DOI: 10.2307/778976

RIQUELME, Roberto (2007). «Episteme». Estudios Visuales, 4.

TAYLOR, Charles (1986). «Foucault on Freedom and Truth». En Couzens, David (Ed.). Foucault. A critical reader. Nueva York: Basil Blackwell. 